\title{
Factors associated with the occurrence of MRSA CC398 in herds of fattening pigs in Germany
}

Katja Alt, Alexandra Fetsch, Andreas Schroeter, Beatriz Guerra, Jens A Hammerl, Stefan Hertwig, Natalja Senkov, Anna Geinets, Christine Mueller-Graf, Juliane Braeunig, Annemarie Kaesbohrer, Bernd Appel, Andreas Hensel and Bernd-Alois Tenhagen ${ }^{*}$

\begin{abstract}
Background: The purpose of this study was to investigate the prevalence of MRSA in herds of fattening pigs in different regions of Germany, and to determine factors associated with the occurrence of this pathogen. For this purpose pooled dust samples were collected, and a questionnaire covered information regarding herd characteristics and management practices. Samples were pre-enriched in high-salt medium followed by selective enrichment containing cefoxitin/aztreonam, and culturing. Presumptive colonies were confirmed by multiplex-PCR targeting nuc-, mecA- and $16 \mathrm{~S}$ rRNA-genes. Isolates were spa- and SCCmec-, and in selected cases, multilocus sequence-typed. Susceptibilities to 13 antimicrobials were determined by broth microdilution. Statistical analysis was carried out using backward stepwise logistic regression to calculate odds ratios with the MRSA test result as the outcome and herd characteristics as categorical covariates.

Results: Overall, 152 of 290 (52\%) fattening pig farms tested positive for MRSA. The prevalence in the east, northand south-west of Germany ranged from 39 to $59 \%$.

t011 (66\%) and t034 (23\%) were the most commonly identified spa-types, and 85\% of isolates carried SCCmec Type V. Identified spa-types were all associated with clonal complex CC398. Susceptibility testing revealed that all isolates were resistant to tetracycline. High resistance rates were also found for sulfamethoxazole/trimethoprim (40\%), and quinupristin/dalfopristin (32\%). In addition, 83\% of strains displayed multidrug resistant (> 3 substance classes) phenotypes.

Logistic regression revealed herd size (large farms OR: 5.4; Cl: 2.7-11.2; $\mathrm{p}<0.05$ ), and production type (wean-tofinish OR: 4.0; $\mathrm{Cl}: 1.6-10.4 ; \mathrm{p}<0.05)$ as risk factors associated with a positive MRSA finding in fattening pig operations.

Conclusions: MRSA CC398 is widely distributed among herds of fattening pigs in Germany. Farm management plays a crucial role in the dissemination of MRSA with herd size, and production type representing potential major indicators.
\end{abstract}

\section{Background}

In recent years, the emergence of the MRSA multilocus sequence type (MLST) CC398 has been reported in livestock in Europe and North America mainly in pigs, but also in veal calves and poultry [1-4]. Characteristic for this newly identified type are its wide spread among livestock and persons in close contact with colonised animals, and its low morbidity.

\footnotetext{
* Correspondence: bernd-alois.tenhagen@bfr.bund.de Federal Institute for Risk Assessment, Thielallee 88-92, D-12277 Berlin, Germany
}

(c) 2011 Alt et al; licensee BioMed Central Ltd. This is an Open Access article distributed under the terms of the Creative Commons Attribution License (http://creativecommons.org/licenses/by/2.0), which permits unrestricted use, distribution, and reproduction in any medium, provided the original work is properly cited.
Animal disease involving MRSA CC398 has been described, especially in horses [5-7] and dairy cattle [8]. In addition, CC398 has been associated with severe diseases in humans [9-12]. Currently the only route of transmission considered playing a relevant role in the transmission of MRSA CC398 from animals to humans is direct contact with colonised livestock [13]. Cross-transmission by contact between humans and pigs or veal calves led to the classification of persons occupationally exposed to pigs or veal calves, e. g. farmers, veterinarians and slaughterhouse staff as high risk population for the carriage of MRSA CC398 [14,15]. 
Typically, livestock isolates display a variety of multiresistant profiles, including resistance to $\beta$-lactams and tetracycline in most of them. It has been shown, that phenotypic resistance to several antimicrobials largely used in clinical practice is encoded by genes located on mobile elements, which reflects the potential for spread and acquisition of new traits, and the relevance of monitoring $[16,17]$.

In order to evaluate the risk posed to humans, and to assess possible routes of transmission, several studies have been undertaken to estimate the prevalence of MRSA CC398 focussing on the pig population as a starting point. At herd level, prevalence of MRSA CC398 has been reported with $45 \%$ positive farms in North America, and ranging between 0 and $46 \%$ among breeding holdings in European Union Member States [2,4,18]. Data from The Netherlands showed 39\% prevalence at pig and $81 \%$ at batch level, when pigs at slaughter were tested [1]. In Germany, the Federal Institute for Risk Assessment (BfR) conducted in 2007 in cooperation with two federal states a survey in abattoirs revealing that up to $71 \%$ of 520 pigs, and 51 of 52 batches were MRSA positive [19]. In 2008, 201 breeding pig herds distributed across Germany were examined in the framework of an EU-wide survey according to Commission Decision 2008/55/EC. Of those, $42 \%$ tested positive [20]. The purpose of the present study was to estimate of the prevalence of MRSA CC398 in dust samples taken in the finishing compartments in German fattening pig farms of different types. Additionally, we assumed that regional differences in the management structures should be reflected in a different MRSA prevalence among fattening herds. To assess these hypotheses we examined fattening pig farms of different management structures located in distinct regions of Germany and determined potential risk factors for the dissemination of MRSA CC398. The current study provides additional information regarding the distribution of MRSA CC398 among swine population, and describes molecular and phenotypic resistance characteristics of collected isolates. Furthermore, factors that potentially play key roles in the spread of this pathogen among swine are outlined.

\section{Results}

\section{Prevalence of MRSA}

A total of 290 operations housing more than 100 finishers distributed across seven federal states agreed to take part in the survey. These operations were allocated to three regions. The north-western (NW) region was represented by 72 , the eastern (E) by 65 , and the south-west (SW) by 153 operations. A brief overview of the prevalence according to the main farm characteristics is provided in Table 1.

Overall, 152 (52\%) herds tested positive for MRSA. The prevalence in the SW was $59 \%, 51 \%$ in the NW, and $39 \%$ in the E. The prevalence of MRSA varied at state level between 29 and 70\% (data not shown).

\section{Molecular typing results}

All isolates were assigned to the clonal complex CC398 by spa-typing. Altogether, twelve different spa-types were identified (Table 2). The vast majority of isolates belonged to types t011 (66\%) and t034 (23\%). One new spa-type, t5488, was detected. Isolates carried primarily (85\%) SCCmec-type V followed by $11 \%$ type $\mathrm{V}^{*}$ (a variant first identified as III) [21]. In one case type IVa was found, and five isolates were not typable after the method previously described [22]. The most frequent combinations of spaand SCCmec-types were t011/V (63\%), t034/V (13\%) and t034/ $\mathrm{V}^{*}$ (9\%) (Table 2).

MLST was performed once for spa-types $\mathrm{t} 2997, \mathrm{t} 2582$, t1451, t5488, and t2383 revealing in all cases sequence type ST398.

\section{Antimicrobial resistance profiles, and application of antimicrobials at group level}

Susceptibility testing results are shown in Table 3. Overall, 45 resistance profiles were detected. Twenty two (15\%) isolates displayed the most common resistance profile TET-OXA. Multidrug resistance (MDR) to a range of three to eight substance classes was found in 126 (83\%) of strains. Among those, the most predominant MDR profiles were OXA-TET-ERY-CLI-QUI/DAL (13\%), and OXA-TET-ERY-CLI-KAN-GEN-SXT-QUI/DAL (10\%). Interestingly, the latter was exclusively associated with spa-type t011. Resistance to SXT was observed in 17 resistance profiles of which 16 were MDR profiles. QUI/DAL resistance occurred in 13 resistance profiles always associated with resistance to four or more substance classes (data not shown).

The majority (57\%) of operations reported the application of antimicrobials as group medication during the fattening period. The reported spectrum of applied antimicrobials was broad, with tetracyclines (28\%), macrolide/lincosamide antibiotics (25\%) and beta-lactams (22\%) constituting the most commonly administered classes of antibiotics in the survey. Up to five different substances were reported at farm level. MRSA was detected in $60 \%$ farms with reported, and in $42 \%$ with no reported antibiotic use at group level. Application of antibiotics was associated (OR: 2.1; CI: 1.3 - 3.4) with the presence of MRSA in the univariate analysis only (Table 1).

\section{Association of farm characteristics with test outcome}

Eight factors (region, herd size, production type, flooring, purchase of pigs, use of antimicrobials, keeping of cattle in the farm, and animal flow system) with a significant univariate association with the test outcome based on a 
Table 1 Results of logistic regression for univariate and multivariate models Only cases with full information on the analysed variable or set of variables were included

\begin{tabular}{|c|c|c|c|c|c|c|c|c|c|}
\hline \multirow[t]{2}{*}{ Variable } & \multirow[t]{2}{*}{ Category } & \multirow[t]{2}{*}{ No. } & \multirow[t]{2}{*}{ Positive $\%$} & \multicolumn{2}{|c|}{ Univariate } & \multicolumn{4}{|c|}{ Multivariate } \\
\hline & & & & $\mathrm{OR}^{\mathrm{a}}$ & $\begin{array}{c}-95 \\
\% \mathrm{Cl}\end{array}$ & $+95 \% \mathrm{Cl}$ & $\mathrm{OR}^{\mathrm{a}}$ & $\begin{array}{c}-95 \\
\% \mathrm{Cl}\end{array}$ & $+95 \% \mathrm{Cl}$ \\
\hline \multirow[t]{3}{*}{ Region } & East & 65 & 39 & Ref & & & & & \\
\hline & Northwest & 72 & 51 & 1.7 & 0.9 & 3.3 & 2.6 & 1.2 & 5.8 \\
\hline & Southwest & 153 & 59 & 2.3 & 1.3 & 4.1 & 3.8 & 1.9 & 7.9 \\
\hline \multirow[t]{3}{*}{ Herd size } & Small & 83 & 30 & Ref & & & & & \\
\hline & Medium & 87 & 60 & 3.5 & 2.7 & 7.2 & 3.8 & 1.9 & 7.5 \\
\hline & Large & 116 & 63 & 3.4 & 1.8 & 6.5 & 5.4 & 2.7 & 11 \\
\hline \multirow[t]{3}{*}{ Production type } & Farrow-to-finish & 65 & 31 & Ref & & & & & \\
\hline & Wean-to-finish & 38 & 63 & 3.9 & 1.7 & 9.0 & 4.0 & 1.6 & 10 \\
\hline & Grow-to-finish & 185 & 58 & 3.1 & 1.7 & 5.6 & 2.0 & 1.0 & 4.0 \\
\hline \multirow[t]{3}{*}{ Purchase of pigs } & No purchase & 73 & 36 & Ref & & & & & \\
\hline & Purchase from 1-2 sources & 165 & 55 & 2.2 & 1.3 & 3.9 & & & \\
\hline & Purchase from multiple sources & 49 & 71 & 4.5 & 2.1 & 9.9 & & & \\
\hline \multirow[t]{3}{*}{ Animal flow system } & Continuous & 90 & 40 & Ref & & & & & \\
\hline & $\mathrm{Al} / \mathrm{AO}^{\mathrm{b}}$ with cleanup & 22 & 46 & 1.3 & 0.5 & 3.2 & & & \\
\hline & $\mathrm{Al} / \mathrm{AO}^{\mathrm{b}}$ with cleanup and disinfection & 154 & 59 & 2.2 & 1.3 & 3.4 & & & \\
\hline \multirow[t]{3}{*}{ Flooring } & Concrete with bedding & 25 & 16 & Ref & & & & & \\
\hline & Partially slatted & 41 & 44 & 7.1 & 2.4 & 21 & & & \\
\hline & Totally slatted & 219 & 58 & 4.1 & 1.2 & 14 & & & \\
\hline \multirow[t]{2}{*}{ Cattle in the farm } & Present & 235 & 56 & Ref & & & & & \\
\hline & Absent & 55 & 36 & 0.5 & 0.2 & 0.8 & & & \\
\hline \multirow[t]{2}{*}{ Use of antimicrobials ${ }^{c}$} & No & 126 & 42 & Ref & & & & & \\
\hline & Yes & 164 & 60 & 2.1 & 1.3 & 3.4 & & & \\
\hline
\end{tabular}

Categories with the lowest MRSA prevalence were chosen as references (indicated as Ref).

${ }^{a}$ p-value $<0.05$

${ }^{b}$ All in/all out

${ }^{\mathrm{c}}$ Reported treatments at group level

p-value $<0.05$ were subjected to further Chi-squared tests to detect correlations among themselves. The correlation matrix revealed strong multicollinearity (data not shown), especially for the variable "region", which was then included as a fixed variable in the regression model.
The multivariate logistic regression analysis included 273 cases with full information on the factors significantly associated with the test outcome $(\mathrm{n}=8)$ according to Chi-squared test. The results of univariate and multivariate logistic regression are summarized in Table 1.

Table 2 Distribution of spa-types and their combinations with identified SCCmec-types among 152 MRSA isolates

\begin{tabular}{|c|c|c|c|c|c|}
\hline Spa-type & $\begin{array}{l}\text { Number of isolates } \\
(\%)\end{array}$ & $\begin{array}{c}\text { SCCmec-type } \mathrm{V}^{*} \\
(\%)\end{array}$ & $\begin{array}{c}\text { SCCmec-type IVa } \\
(\%)\end{array}$ & $\begin{array}{c}\text { SCCmec-type V } \\
(\%)\end{array}$ & $\begin{array}{c}\mathrm{SCCmec} \text { non typeable } \\
(\%)\end{array}$ \\
\hline t011 & $101(66)$ & $1(0.7)$ & $1(0.7)$ & $96(63)$ & $3(2.0)$ \\
\hline t034 & $35(23)$ & $14(9.2)$ & & 19 (13) & $2(1.4)$ \\
\hline $\mathrm{t} 108$ & $4(2.6)$ & & & $4(2.6)$ & \\
\hline t571 & $2(1.3)$ & & & $2(1.4)$ & \\
\hline $\mathrm{t} 1255$ & $1(0.7)$ & & & $1(0.7)$ & \\
\hline t1451 & $3(2.0)$ & & & $3(2.1)$ & \\
\hline t1928 & $1(0.7)$ & $1(0.7)$ & & & \\
\hline t2383 & $1(0.7)$ & & & $1(0.7)$ & \\
\hline $\mathrm{t} 2510$ & $1(0.7)$ & & & $1(0.7)$ & \\
\hline t2582 & $1(0.7)$ & $1(0.7)$ & & & \\
\hline t2997 & $1(0.7)$ & & & $1(0.7)$ & \\
\hline t5488 & $1(0.7)$ & & & $1(0.7)$ & \\
\hline Total & $152(100)$ & $17(11)$ & $1(0.7)$ & $129(85)$ & $5(3.3)$ \\
\hline
\end{tabular}


Table 3 Distribution of MIC values for MRSA CC398 identified in this study

\begin{tabular}{|c|c|c|c|c|c|c|c|c|c|c|c|c|c|}
\hline \multirow[b]{2}{*}{ Antimicrobial agent(s) } & \multicolumn{11}{|c|}{ No. of isolates with MIC (mg/L) } & \multicolumn{2}{|c|}{$\begin{array}{c}\text { Resistant } \\
\text { (non-wild-type) }\end{array}$} \\
\hline & 0.25 & 0.5 & 1 & 2 & 4 & 8 & 16 & 32 & 64 & 128 & 256 & no. & $\%$ \\
\hline $\mathrm{OXA}+2 \% \mathrm{NaCl}$ & - & 4 & 2 & 1 & 10 & 57 & 78 & - & - & - & - & 145 & 95 \\
\hline ERY & 4 & 45 & 10 & 0 & 0 & 0 & 0 & 93 & - & - & - & 93 & 61 \\
\hline CLI & 48 & 6 & 1 & 0 & 1 & 1 & 4 & 90 & 1 & - & - & 104 & 68 \\
\hline TET & - & - & 0 & 0 & 0 & 0 & 0 & 1 & 37 & 114 & - & 152 & 100 \\
\hline $\mathrm{CHL}$ & - & - & - & 0 & 2 & 58 & 82 & 4 & 4 & 2 & 0 & 10 & 6.6 \\
\hline GEN & - & 57 & 48 & 14 & 4 & 3 & 3 & 6 & 4 & 13 & - & 33 & 22 \\
\hline KAN & - & - & - & - & - & 77 & 23 & 15 & 10 & 3 & 24 & 75 & 49 \\
\hline CIP & - & 134 & 10 & 2 & 3 & 3 & 0 & 0 & 0 & - & - & 8 & 5.3 \\
\hline$S X T^{b}$ & 66 & 24 & 40 & 18 & 3 & 1 & 0 & - & - & - & - & 61 & 40 \\
\hline QUI/DAL & - & 52 & 52 & 25 & 12 & 5 & 6 & - & - & - & - & 48 & 32 \\
\hline MUP & - & - & 152 & 0 & 0 & 0 & 0 & - & - & - & - & 0 & 0.0 \\
\hline LZD & - & - & 5 & 56 & 91 & 0 & 0 & - & - & - & - & 0 & 0.0 \\
\hline VAN & - & - & - & 152 & 0 & 0 & 0 & 0 & - & - & - & 0 & 0.0 \\
\hline
\end{tabular}

OXA: oxacillin, ERY: erythromycin, CLI: clindamycin, TET: tetracycline, CHL: chloramphenicol, GEN: gentamicin, KAN: kanamycin, CIP: ciprofloxacin, SXT: sulfamethoxazole/trimethoprim, QUI/DAL: quinupristin/dalfopristin, MUP: mupirocin, LZD: linezolid, and VAN: vancomycin.

${ }^{a}$ Isolates were classified as resistant after EUCAST epidemiological cut-off values (black vertical lines) for MRSA and/or S. aureus valid at the time of submission.

b The MIC values of sulfamethoxazole/trimethoprim (19:1) are given as trimethoprim MIC values.

Dilution ranges tested are framed by -. Isolates resistant to the highest tested concentration are given in the next concentration level (bold). Values for the lowest concentration include isolates with MICs below the tested range.

The multivariate model comprises the variables herd size, and production type. Large (> 1000 finishers) and medium-sized (500-999 finishers) farms were more likely to harbour MRSA compared to small operations housing less than 500 fatteners. Production types wean-to-finish and grow-to-finish were also associated with a higher likelihood of a MRSA finding in the herd. In the univariate analysis the purchase of pigs showed an impact on the MRSA test. A distribution of the positive MRSA results among farm characteristics according to the purchase of pigs is shown in Table 4. Operations that obtained their growers from specialized farms that purchase weaners to sell them as growers for fattening (weaner-to-grower producers), tested positive for MRSA $(n=5)$. Since only five operations in this purchase category took part in the study, and on account of the various origins of weaners in weaner-to-grower productions, the categories "purchase from $>2$ sources" and "purchase from weaner-to-grower producers" were combined to the category "purchase from multiple sources" for logistic regression analysis.

The final logistic regression analysis to test robustness showed that the variables herd size and production type had a stable predictive value in all seven data subsets (data not shown).

\section{Discussion}

The present study reflects the wide dissemination of MRSA CC398 among German herds of fattening pigs. Additionally, farms that harbour more than 500 finishers, and wean- as well as grow-to-finish production types were identified as risk factors for a positive MRSA test result.

From a production chain point of view, the fattening sector takes a middle position between breeding pig herds and the slaughter pigs previously studied in Germany $[19,20]$. Although the three studies are not longitudinally connected, their results, and the pyramidal structure of pig production are in line with the vertical dissemination of MRSA from breeding (top) to production holdings (bottom; from fattening to slaughter pigs), when considered at herd level. Within herds, it has been observed that age has an impact on MRSA prevalence among pigs, and that there seems to be a strong decline in pig colonization towards the time of slaughter [23-25]. However, agedependant differences in MRSA prevalence among finishing pigs were not addressed by our study design, since samples were taken within the same broad age group (10 30 weeks) among farms of different types.

In the present study, three farm production types were targeted. The prevalence for MRSA in wean- and grow-tofinish production holdings exceeded $58 \%$. By contrast, farrow-to-finish operations tested only in $31 \%$ positive, on average. Multicollinearity among variables is a limitation of the present study that hampers the interpretation of the effect of a single factor on MRSA prevalence. The variable "production type" strongly correlated with the "purchase of pigs" $\left(\chi^{2}, \mathrm{p}<0,001\right)$. The production types covered by this study differed in their purchase patterns of pigs for fattening. While wean- and grow-to-finish operations bought piglets in 76 and $95 \%$ of cases respectively, only 
Table 4 MRSA prevalence in herds with different properties according to the reported purchase of piglets

\begin{tabular}{|c|c|c|c|c|c|c|}
\hline Variable & Category & $\begin{array}{c}\text { No } \\
\text { purchase } \\
\text { No. (\% pos.) }\end{array}$ & $\begin{array}{l}\text { Purchase from 1-2 } \\
\text { sources } \\
\text { No. (\% pos.) }\end{array}$ & $\begin{array}{l}\text { Purchase from }>2 \\
\text { sources } \\
\text { No. (\% pos.) }\end{array}$ & $\begin{array}{l}\text { Purchase from weaner-to-grower } \\
\text { producers } \\
\text { No. }(\% \text { pos.) }\end{array}$ & $\begin{array}{l}\text { Total } \\
\text { No. }(\% \\
\text { pos.) }\end{array}$ \\
\hline \multirow[t]{4}{*}{ Herd size } & Small & $34(21)$ & $40(38)$ & $7(29)$ & $1(100)$ & $82(31)$ \\
\hline & Middle & $18(56)$ & $48(56)$ & $16(69)$ & $4(100)$ & $86(61)$ \\
\hline & Large & $19(42)$ & $75(64)$ & $21(81)$ & $0(0.0)$ & $115(64)$ \\
\hline & Total & $71(35)$ & $163(55)$ & $44(68)$ & $5(100)$ & $283(53)$ \\
\hline \multirow[t]{4}{*}{ Production type } & Farrow-to-finish & $53(30)$ & $8(25)$ & $3(67)$ & $0(0.0)$ & $64(31)$ \\
\hline & Wean-to-finish & $9(56)$ & $25(64)$ & $3(67)$ & $1(100)$ & $38(63)$ \\
\hline & Grow-to-finish & $10(50)$ & $132(55)$ & $37(68)$ & $4(100)$ & $183(59)$ \\
\hline & Total & $72(36)$ & $165(55)$ & $43(67)$ & $5(100)$ & $285(53)$ \\
\hline \multirow[t]{4}{*}{ Animal flow system } & Continuous & $36(25)$ & $43(47)$ & $9(78)$ & $0(0.0)$ & $88(41)$ \\
\hline & AIAO ${ }^{a}$ with cleanup & $2(0.0)$ & $16(44)$ & $4(75)$ & $0(0.0)$ & $22(46)$ \\
\hline & $\begin{array}{l}\mathrm{AlAO}^{\mathrm{a}} \text { with cleanup and } \\
\text { disinfection }\end{array}$ & $34(50)$ & $105(60)$ & $29(62)$ & $5(100)$ & $173(60)$ \\
\hline & Total & $72(36)$ & $164(55)$ & $42(67)$ & $5(100)$ & $283(53)$ \\
\hline \multirow{3}{*}{$\begin{array}{l}\text { Use of } \\
\text { antimicrobials }^{\mathrm{b}}\end{array}$} & No & $45(27)$ & $64(52)$ & $15(53)$ & $0(0.0)$ & $124(43)$ \\
\hline & Yes & $28(50)$ & $101(57)$ & $29(76)$ & $5(100)$ & $163(61)$ \\
\hline & Total & 73 (36) & 165 (55) & $44(68)$ & $5(100)$ & $287(53)$ \\
\hline
\end{tabular}

${ }^{a}$ All in/all out

${ }^{\mathrm{b}}$ Reported treatments at group level 
$17 \%$ of farrow-to-finish herds purchased pigs. Furthermore, the size of herds is a risk factor for the presence of MRSA CC398 in a pig farm [26]. This reflects that intensive pig rearing implicates a greater pool of potential recipients. In the present survey, the prevalence of MRSA among middle-sized and large farms increased with the number of sources of pigs reaching $81 \%$ positives when pigs were purchased from multiple ( $>2$ ) sources. By contrast, the prevalence in small farms achieved a maximum of $38 \%$ when pigs were bought from one to two sources. Overall, middle-sized and large farms bought in 79 and $86 \%$ of cases pigs, compared to $59 \%$ of small farms. Chisquared test also indicated a link between size of farms and purchase policy $\left(\chi^{2}, \mathrm{p}=0,001\right)$. It has already been proposed, that MRSA is spread between farms via trade of colonized animals [27]. However, purchase alone does not explain a high MRSA prevalence, since grow-to-finish operations purchased pigs most frequently of all production types, but did not show the highest MRSA prevalence. It is most likely that certain trade flows are responsible for the circulation of MRSA CC398. Other drivers also may play a role in the spread of MRSA, such as an aerogen transmission in regions with high livestock density or vector borne transmission between farms. In addition, intraherd factors should be investigated, since MRSA CC398 also occurs in closed herds implementing tighter biosecurity measures than in production holdings [20].

The collected data do not allow a sound comparison between regions, since the aimed sample size $(n=170)$ for each region was only reached in the southwest of Germany, in which the highest prevalence (59\%) was observed.

Molecular characterization of the isolates mirrors the reported variety of strains in Europe [11,20,28]. The high diversity of resistance profiles detected is in line with previous investigations [16,17]. Some mecA-positive isolates were phenotypically susceptible to oxacillin. This has previously been reported and may in part be explained by heteroresistance [29]. To address this observation properly, additional investigations would be required which were not part of the present study. We identified a high proportion of resistant isolates to the combinations quinupristin/dalfopristin (32\%) and sulfamethoxazole/trimethoprim (40\%). Phenotypic resistance to quinupristin/dalfopristin (QUI/DAL) and sulfamethoxazole/trimethoprim in MRSA CC398 has already been reported, however, not at such high rates $[16,30]$. Resistance to the streptogramin A and B combination QUI/DAL is of concern since the compound represents an alternative to glycopeptides in therapy of human MRSA infections. Argudín et al. were not able to detect any of the genes coding for resistance to streptogramin $A$ and $B$ vat $A, v a t B, v a t C, v g a A, v g a B, v g a C, v g b A$ and $v g b B$ in 9 MRSA CC398 isolates phenotypically resistant to QUI/DAL [16], suggesting the isolates were not truly resistant or other mechanisms are responsible for resistance. The currently valid epidemiological cut-off for interpretation of resistance to QUI/DAL is quite low $(\geq 2)$. Further analyses would be required to identify the underlying genetic mechanisms. Comparison of our results with MIC distributions for MRSA CC398 from previous studies reveals similar proportions of non-wildtype (resistant) phenotypes [1,30]. However, a high proportion of $(83 \%)$ multidrug resistant isolates were found in this study, including resistance to the combinations quinupristin/dalfopristin and sulfamethoxazole/trimethoprim in the two most predominant MDR profiles. An association between certain resistance phenotypes and the widespread spa-type t011, as our results indicate, requires further clarification.

\section{Conclusions}

The results of the present study reveal a high prevalence of MRSA CC398 in German fattening pig herds, mainly in large herds and wean-to-finish operations. The implication of pig trade and other factors in the spread of this microorganism requires further investigation since MRSA has been detected to a high extent in German breeding and closed breeding (nucleus) herds [20].

Identified SCCmec- and spa-types confirm circulating clones in the European pig industry. Susceptibility testing reveals a high amount of quinupristin/dalfopristin and sulfamethoxazole/trimethoprim non-wild-type phenotypes.

\section{Methods \\ Survey design}

In the period between May and December 2008, federal states of Germany were asked to collaborate in the present study to determine the spread of MRSA in herds of fattening pigs. Following the technical specifications in the course of the EU-wide survey in breeding pig herds as outlined in Commission Decision 2008/55/EC, the sampling plan aimed to collect five dust samples from different positions within the compartments with fattening pigs between 10 and 30 weeks of age of randomly chosen operations housing more than 100 finishers. Sample size was calculated based on an estimated prevalence of $50 \%$, a $95 \%$ confidence interval, and $7.5 \%$ accuracy. To obtain representative results for Germany the sampling plan aimed to enrol a total of 510 herds located in the eastern $(n=170)$, north- $(n=170)$ and south-western $(n=170)$ regions of Germany, distributed within each region among federal states according to the proportion of fattening pig operations with > 100 animals. A questionnaire was used to determine the herd size, animal flow system, production type, flooring, health status in the herd, and application of antimicrobials as group 
medication in a four-month interval prior to sampling (fattening period), location of the operation, and housing of other animal species. Details of collected data are given in Table 1. The official veterinarian in charge of the region was assigned with the collection of the samples and completion of the questionnaire. Collected samples were shipped at room temperature within 10 days to accredited regional laboratories or optionally to the National Reference Laboratory for Coagulase Positive Staphylococci incl. S. aureus (NRL Staph) at the BfR for primary isolation of MRSA 13 days after sampling at the latest. Sample collection, shipping and storage complied with the methods described in Commission Decision 2008/55/EC

Primary isolates obtained at regional laboratories were sent for confirmation, further typing and antimicrobial susceptibility testing of MRSA to the NRL Staph.

\section{Bacterial culturing}

Primary isolation was performed in all laboratories as follows and in accordance with Commission Decision 2008/ $55 /$ EC. Samples were pooled per farm and cultured for pre-enrichment in Mueller Hinton broth supplemented with $6.5 \% \mathrm{NaCl}$. After incubation for $16-20 \mathrm{~h}$ at $37^{\circ} \mathrm{C}, 1 \mathrm{ml}$ was inoculated into $9 \mathrm{ml}$ of tryptic soy broth containing $3.5 \mu \mathrm{g} / \mathrm{ml}$ cefoxitin and $75 \mu \mathrm{g} / \mathrm{ml}$ aztreonam, and incubated again at $37^{\circ} \mathrm{C}$ for $16-20 \mathrm{~h}$. A loopful was then plated onto sheep blood agar and chromogenic MRSA screening agar (Brilliance MRSA Agar, Oxoid, Wesel, Germany, and/or CHROMagar MRSA, Mast Diagnostica, Reinfeld, Germany). After incubation for $24-48 \mathrm{~h}$ at $37^{\circ} \mathrm{C}$ regional laboratories sent five presumptive colonies as subcultures to the NRL Staph for confirmation.

\section{SCCmec- and spa-typing}

DNA extraction was performed using the "RTP ${ }^{\circledR}$ Bacteria DNA Mini Kit" (Invitek, Berlin, Germany). MRSA isolates were confirmed by multiplex PCR targeting 16S rRNA-, nuc-, and mecA-genes, as described previously [31].

Further characterization of the isolates involved SCCmec-typing for the identification of types I-V [22], and spa-typing [32]. One MRSA isolate of each positive farm was SCCmec- and spa-typed. A multilocus sequence type (ST) was determined for selected spa-types [33]. Sequencing of PCR products was conducted by Agowa, Berlin, Germany.

Spa-types were assigned using the Ridom StaphType software (Ridom GmbH, Würzburg, Germany), and MLST sequence analysis was carried out by matching with $S$. aureus MLST database (http://saureus.mlst.net).

\section{Antimicrobial susceptibility testing}

Susceptibility tests were carried out using the broth microdilution method according to CLSI guidelines [34].
Custom-made microtitre plate panels were used (TREK Diagnostic Systems, Magellan Biosciences, West Sussex, England). Overall, susceptibilities to 13 antimicrobial agents/combinations of agents were determined and for each, 5-8 concentrations in 2-fold dilution series were tested (Table 3). S. aureus strain ATCC 25923 was used as a control. Evaluation of resistance was based on epidemiological cut-off values published by the European committee for antimicrobial susceptibility testing for MRSA and S. aureus (http://www.eucast.org).

\section{Statistics}

Data analysis was performed using the statistical software program SPSS 18.0 (SPSS Inc. Munich, Germany). Univariate analysis was performed using Chi-squared test to select for herd parameters significantly associated (p-value $<0.05$ ) with the test outcome, and to estimate correlations among variables. Multivariate analysis of the data included backward stepwise binary logistic regression with the test result as the outcome (negative $=0 /$ positive $=1)$ and the herd characteristics as categorical covariates to estimate odds ratios (OR) including those variables significantly associated with the outcome in the univariate analysis. For this purpose, only cases with complete information on variables included in the model were considered.

To test the robustness of the model, the original sample $(\mathrm{n}=290)$ was randomly divided into seven sub-samples ( 41 cases each), and then subjected seven times to stepwise binary logistic regression each time excluding one of the subsamples.

\section{Acknowledgements}

The authors gratefully acknowledge the full support received from the regional authorities and laboratories. In addition, the authors would like to thank U. Kaempe, J. Kowall, A. Beyermann and B. Kraushaar for excellent technical support. The project was funded by the German Ministry of Food, Agriculture and Consumer Protection (BMELV) (project no. 2808HS032).

\section{Authors' contributions}

KA carried out data analyses and drafted the manuscript. AF participated in the microbiological testing of the strains. JAH and $\mathrm{SH}$ carried out the molecular genetic studies. AS and BG were responsible for susceptibility testing of the strains. NS, AG and CMG investigated statistical analyses made by $\mathrm{KA}$. JB, AK, AH and BA contributed to the drafting of the manuscript. BAT is responsible for study design and coordination, and helped to draft the manuscript. All authors read and approved the final manuscript.

Received: 13 December 2010 Accepted: 10 November 2011 Published: 10 November 2011

\section{References}

1. de Neeling AJ, van den Broek MJ, Spalburg EC, van Santen-Verheuvel MG, Dam-Deisz WD, Boshuizen HC, van de Giessen AW, van Duijkeren $E$, Huijsdens XW: High prevalence of methicillin resistant Staphylococcus aureus in pigs. Vet Microbiol 2007, 120:366-372.

2. Khanna T, Friendship R, Dewey C, Weese JS: Methicillin resistant Staphylococcus aureus colonization in pigs and pig farmers. Vet Microbiol 2008, 128:298-303. 
3. Persoons D, Van Hoorebeke S, Hermans K, Butaye P, de Kruif A, Haesebrouck F, Dewulf J: Methicillin-resistant Staphylococcus aureus in poultry. Emerg Infect Dis 2009, 15:452-453.

4. Smith TC, Male MJ, Harper AL, Kroeger JS, Tinkler GP, Moritz ED, Capuano AW, Herwaldt LA, Diekema DJ: Methicillin-resistant Staphylococcus aureus (MRSA) strain ST398 is present in midwestern U. S. swine and swine workers. PLOS ONE 2008, 4:e4258.

5. Cuny C, Strommenger B, Witte W, Stanek C: Clusters of infections in horses with MRSA ST1, ST254, and ST398 in a veterinary hospital. Microb Drug Resist 2008, 14:307-310.

6. Nemati M, Hermans K, Lipinska U, Denis O, Deplano A, Struelens M, Devriese LA, Pasmans F, Haesebrouck F: Antimicrobial resistance of old and recent Staphylococcus aureus isolates from poultry: first detection of livestock-associated methicillin-resistant strain ST398. Antimicrob Agents Chemother 2008, 52:3817-3819.

7. van Duijkeren E, Moleman M, Sloet van Oldruitenborgh-Oosterbaan MM Multem J, Troelstra A, Fluit AC, van Wamel WJ, Houwers DJ, de Neeling AJ, Wagenaar JA: Methicillin-resistant Staphylococcus aureus in horses and horse personnel: An investigation of several outbreaks. Vet Microbiol 2009, 141:96-102.

8. Spohr M, Rau J, Friedrich A, Klittich G, Fetsch A, Guerra B, Hammerl JA, Tenhagen BA: Methicillin-resistant Staphylococcus aureus (MRSA) in three dairy herds in southwest Germany. Zoonoses Public Health 2011, 58:252-261.

9. Ekkelenkamp MB, Sekkat M, Carpaij N, Troelstra A, Bonten MJ: [Endocarditis due to meticillin-resistant Staphylococcus aureus originating from pigs]. NederlandsTijdschrift for Geneeskunde 2006, 150:2442-2447.

10. Huijsdens XW, van Dijke BJ, Spalburg E, Santen-Verheuvel MG, Heck ME, Pluister GN, Voss A, Wannet WJ, de Neeling AJ: Community-acquired MRSA and pig-farming. Ann Clin Microbiol Antimicrob 2006, 5:26.

11. Witte W, Strommenger B, Stanek C, Cuny C: Methicillin-resistant Staphylococcus aureus ST398 in humans and animals, Central Europe. Emerg Infect Dis 2007, 13:255-258

12. Wulf M, van Nes A, Eikelenboom-Boskamp A, de Vries J, Melchers W, Klaassen C, Voss A: Methicillin-resistant Staphylococcus aureus in veterinary doctors and students, the Netherlands. Emerg Infect Dis 2006, 12:1939-1941

13. Cuny C, Nathaus R, Layer F, Strommenger B, Altmann D, Witte W: Nasal colonization of humans with methicillin-resistant Staphylococcus aureus (MRSA) CC398 with and without exposure to pigs. PLOS ONE 2009, 4: e6800.

14. Graveland $\mathrm{H}$, Wagenaar JA, Heesterbeek $\mathrm{H}$, Mevius D, van Duijkeren $\mathrm{E}$, Heederik D: Methicillin Resistant Staphylococcus aureus ST398 in Veal Calf Farming: Human MRSA Carriage Related with Animal Antimicrobial Usage and Farm Hygiene. PLOS ONE 2010, 5:e10990.

15. van den Broek I, van Cleef BA, Haenen A, Broens EM, van der Wolf PJ, van den Broek MJ, Huiisdens XW, Kluytmans JA, van de Giessen AW, Tiemersma EW: Methicillin-resistant Staphylococcus aureus in people living and working in pig farms. Epidemiol Infect 2009, 137:700-708.

16. Argudin MA, Tenhagen BA, Fetsch A, Sachsenroder J, Kasbohrer A, Schroeter A, Hammerl JA, Hertwig S, Helmuth R, Braunig J: Virulence and Resistance Determinants of German Staphylococcus aureus ST398 Isolates from Nonhuman Sources. Appl Environ Microbiol 2011, 77:3052-3060.

17. Kadlec K, Ehricht R, Monecke S, Steinacker U, Kaspar H, Mankertz J, Schwarz S: Diversity of antimicrobial resistance pheno- and genotypes of methicillin-resistant Staphylococcus aureus ST398 from diseased swine. $J$ Antimicrob Chemother 2009, 14:1156-1164

18. Nienhoff U, Kadlec K, Chaberny IF, Verspohl J, Gerlach GF, Schwarz S, Simon D, Nolte I: Transmission of methicillin-resistant Staphylococcus aureus strains between humans and dogs: two case reports. J Antimicrob Chemother 2009, 64:660-662.

19. Tenhagen BA, Fetsch A, Stuhrenberg B, Schleuter G, Guerra B, Hammerl JA, Hertwig S, Kowall J, Kampe U, Schroeter A: Prevalence of MRSA types in slaughter pigs in different German abattoirs. Vet Rec 2009, 165:589-593.

20. European Food Safety Authority: Analysis of the baseline survey on the prevalence of methicillin-resistant Staphylococcus aureus (MRSA) in holdings with breeding pigs, in the EU, 2008, Part A: MRSA prevalence estimates; on request from the European Commission. EFSA J 2009, 7:1376.
21. Argudin MA, Fetsch A, Tenhagen BA, Hammerl JA, Hertwig S, Kowall J, Rodicio MR, Kasbohrer A, Helmuth R, Schroeter A: High Heterogeneity within Methicillin-Resistant Staphylococcus aureus ST398 Isolates, Defined by Cfrgl Macrorestriction-Pulsed-Field Gel Electrophoresis Profiles and spa and SCCmec Types. Appl Environ Microbiol 2010, 76:652-658.

22. Zhang K, McClure JA, Elsayed S, Louie T, Conly JM: Novel multiplex PCR assay for characterization and concomitant subtyping of staphylococcal cassette chromosome mec types I to V in methicillin-resistant Staphylococcus aureus. J Clin Microbiol 2005, 43:5026-5033.

23. Willems G, Dispas M, Denis O, Hallin M, Suetens C, Gordts B, Struelens M, Butaye P: Characterisation of MRSA from pigs in Belgium. In 2nd Symposium on antimicrobial resistance in animals and in the environment; 17 December 2007 Edited by: Clockaert A Tours/FR 18.

24. Huber H, Koller S, Giezendanner N, Stephan R, Zweifel C: Prevalence and characteristics of meticillin-resistant Staphylococcus aureus in humans in contact with farm animals, in livestock, and in food of animal origin, Switzerland, 2009. Eurosurveillance 2010, 15:1-4.

25. Weese JS, Rousseau J, Deckert A, Gow S, Reid-Smith R: Clostridium difficile and methicillin-resistant Staphylococcus aureus shedding by slaughterage pigs. BMC Vet Res 2011, 7:41

26. European Food Safety Authority: Analysis of the baseline survey on the prevalence of methicillin-resistant Staphylococcus aureus (MRSA) in holdings with breeding pigs, in the EU, 2008 - Part B: factors associated with MRSA contamination of holdings; on request from the European Commission. EFSA J 2010, 1597.

27. van Duijkeren E, Ikawaty R, Broekhuizen-Stins MJ, Jansen MD, Spalburg EC, de Neeling AJ, Allaart JG, van Nes A, Wagenaar JA, Fluit AC: Transmission of methicillin-resistant Staphylococcus aureus strains between different kinds of pig farms. Vet Microbiol 2008, 126:383-389.

28. Guardabassi L, Stegger M, Skov R: Retrospective detection of methicillin resistant and susceptible Staphylococcus aureus ST398 in Danish slaughter pigs. Vet Microbiol 2007, 122:384-386.

29. Hososaka Y, Hanaki H, Endo H, Suzuki Y, Nagasawa Z, Otsuka Y, Nakae T, Sunakawa K: Characterization of oxacillin-susceptible mecA-positive Staphylococcus aureus: a new type of MRSA. J Infect Chemother 2007, 13:79-86.

30. Fessler A, Scott C, Kadlec K, Ehricht R, Monecke S, Schwarz S: Characterization of methicillin-resistant Staphylococcus aureus ST398 from cases of bovine mastitis. J Antimicrob Chemother 2010, 65:619-625.

31. Poulsen $A B$, Skov R, Pallesen LV: Detection of methicillin resistance in coagulase-negative staphylococci and in staphylococci directly from simulated blood cultures using the EVIGENE MRSA Detection Kit. J Antimicrob Chemother 2003, 51:419-421.

32. Shopsin B, Gomez M, Montgomery SO, Smith DH, Waddington M, Dodge DE, Bost DA, Riehman M, Naidich S, Kreiswirth BN: Evaluation of protein A gene polymorphic region DNA sequencing for typing of Staphylococcus aureus strains. J Clin Microbiol 1999, 37:3556-3563.

33. Enright MC, Day NP, Davies CE, Peacock SJ, Spratt BG: Multilocus sequence typing for characterization of methicillin-resistant and methicillinsusceptible clones of Staphylococcus aureus. J Clin Microbiol 2000, 38:1008-1015.

34. CLSI: Performance Standards for Antimicrobial Disk and Dilution Susceptibility Tests for Bacteria Isolated From Animals-3rd Edition: CLSI document M31-A3. Clinical and Laboratory Standards Institute, Wayne, PA, USA; 2008.

doi:10.1186/1746-6148-7-69

Cite this article as: Alt et al:: Factors associated with the occurrence of MRSA CC398 in herds of fattening pigs in Germany. BMC Veterinary Research 2011 7:69. 